\title{
EFEITO DOS TRATOS SILVICULTURAIS NA PRODUTIVIDADE E NA QUALIDADE DA MADEIRA EM PLANTAÇÕES DE Eucalyptus spp.
}

\author{
Genilson Cordeiro de Sousa ${ }^{1}$; Jadir Vieira da Silva ${ }^{2}$; Claudionor Camilo da Costa ${ }^{3}$ \\ ${ }^{1}$ Tecnólogo em Silvicultura- Instituto Federal de Minas Gerais Campus São João Evangelista CEP 39705-000 \\ São João Evangelista-MG. genilsonxiss@yahoo.com.br; \\ ${ }^{2}$ Universidade Federal dos Vales do Jequitinhonha e Mucuri / Programa de Pós-graduação em Ciência Florestal, \\ Rodovia MG 367, 5000 Alto do Jacuba - 39100-000 - Diamantina-MG, jadirvsilva@yahoo.com.br; \\ ${ }^{3}$ Professor do Instituto Federal de Minas Gerais Campus São João Evangelista CEP 39705-000 \\ São João Evangelista-MG. claudionor.costa@ifmg.edu.br
}

\section{RESUMO}

O presente trabalho descreve os tratamentos culturais que podem ser realizados em plantações de eucalipto, com o intuito de melhorar a produtividade e qualidade da madeira produzida. A escolha do espaçamento inicial de plantio depende do destino final da madeira a ser produzida. O controle de plantas invasoras pode ser de forma manual, mecânica ou química nas linhas e/ou entrelinhas de plantio, este é de suma importância principalmente no estabelecimento da floresta, no qual essas plantas invasoras iram competir pelos recursos do meio com as mudas recém plantadas, retardando o crescimento da floresta. A fertilização pode alterar a estrutura anatômica e a densidade da madeira. A desrama pode melhorar a qualidade da madeira tornando-a isenta de nós. O desbaste é empregado para ampliar o espaço vital, e obter, dessa forma, um maior crescimento em diâmetro das árvores remanescentes.

Palavras-chave: Controle de plantas invasoras, Fertilização, Desrama, Desbaste.

\section{EFFECT OF CULTURAL TREATMENTS IN THE PRODUCTIVITY AND WOOD QUALITY OF Eucalyptus spp. CROPS}

\begin{abstract}
This paper describes the cultural treatments that may be performed in eucalypt plantations, in order to improve productivity and quality of wood produced. The choice of initial planting spacing depends on the final destination of the timber to be produced. The control of invasive plants may be in a manual, mechanical or chemical lines and / or between rows of planting, this is very important especially in the establishment of the forest in which these weeds compete for resources shall go through with the newly planted seedlings, slowing the growth of the forest. Fertilization can change the anatomical structure and wood density. Pruning can improve the quality of the wood making it free of knots. Thinning is used to enlarge the living space, and obtain thus a greater diameter growth of remaining trees.
\end{abstract}

Keywords: Weed control, Fertilization, Pruning, Thinning.

\section{INTRODUÇÃO}

Tratos silviculturais são tratamentos indispensáveis a um povoamento florestal, os quais 
interferem nas condições ambientais em prol do desenvolvimento da floresta. Assim sendo, tratos silviculturais são executados durante o crescimento e maturação da floresta com o objetivo de incrementar a produtividade, melhorar a qualidade e agregar valor à matéria-prima (Pinheiro, 1999; Finger et al., 2001; Berger et al., 2002; Lima, 2005). Práticas como o espaçamento, fertilização, controle de plantas invasoras, a desrama e o desbaste, podem definir a qualidade da madeira (Berger, 2000).

O espaçamento define a densidade de plantio e é um dos principais tratos silviculturais usados para modificar as características da madeira de eucalipto em florestas plantadas (Mello et al., 1976; Berger et al., 2002).

É necessário realizar o controle de plantas invasoras principalmente nas fases iniciais de plantio, onde as mesmas causam maior competição às plantas cultivadas, devido à competição por água, luz e nutrientes minerais, exercida por tais ervas sobre a cultura (Toledo, 2002; Toledo et al., 2003). Toledo (2002) menciona que em plantios florestais, as plantas sofrem sensivelmente a competição das plantas invasoras.

A fertilização é uma prática que visa mudar as características anatômicas, fisiológicas e químicas da madeira através da nutrição mineral (Pinheiro, 1999; Berger, 2000). Pinheiro (1999) afirma que a fertilização em povoamentos florestais pode afetar a estrutura anatômica, e a constituição da parede celular, alterando a densidade da madeira.

Quando o objetivo é produzir madeira para serraria, faz-se necessário a realização de desrama artificial que tem como princípio a retirada de parte dos galhos da árvore para produção de madeira livre de nós (Finger et al., 2001; Vale et al., 2002; Polli, 2005). Polli (2005) cita que por meio da desrama artificial se produz uma madeira com boa qualidade para serraria devido à ausência de nós.
O desbaste é uma prática que visa à retirada de parte das árvores de um povoamento para que as demais tenham menos competição por água, luz e nutrientes minerais, e consequentemente um melhor desenvolvimento (Schneider et al., 1998; Lima et al., 2000; Lima \& Garcia, 2005).

Os tratos silviculturais talvez sejam os investimentos que menos oneram e que trazem o maior retorno na forma de qualidade da produção de madeira e de renda da floresta (Finger \& Schneider, 1999).

Em florestas plantadas, diversas são as práticas silviculturais que devem ser aplicadas, quando o objetivo é a produção de madeira sólida de qualidade. Práticas como variações no espaçamento, controle de plantas invasoras, fertilização, desbaste e desrama, podem definir a qualidade da madeira (Pinheiro, 1999; Berger, 2000; Finger et al., 2001; Berger et al., 2002). Esses autores mencionam que a associação diferenciada de práticas de manejo pode produzir madeira de boa qualidade, principalmente, para indústria à base de produtos sólidos.

No Brasil, embora a fertilização para plantios florestais resulte em ganhos de produtividade, pouca atenção tem sido dada aos efeitos que ela pode ter sobre a qualidade da madeira produzida. São poucas as informações a respeito do efeito da fertilização nas propriedades físicas, mecânicas, químicas e anatômicas da madeira do gênero Eucalyptus (Berger, 2000).

Berger (2000) cita que o espaçamento influencia na massa específica durante o desenvolvimento inicial do povoamento, onde espaçamentos maiores antes do fechamento da copa podem proporcionar um aumento da massa específica. Berger et al., (2002), em trabalho realizado com Eucalyptus saligna, afirmam que o incremento em volume de madeira está associado a uma maior área livre por árvore no campo, onde o aproveitamento fotossintético é mais eficiente. 
Lima (2005), estudando o comportamento de Eucalyptus grandis de 21 anos de idade com fertilização e desbastes em diferentes idades, afirma que o rendimento em madeira serrada não foi afetado pelas práticas silviculturais, no entanto as características de densidade e qualidade da madeira em geral sim. Conclui, ainda, que desbastes crescentes tendem a produzir madeira com características mais homogêneas.

Segundo Polli (2005), são as seguintes as características que indicam a qualidade da madeira para cada finalidade:

a) quando o objetivo é produzir madeira de qualidade para serraria, esta deve possuir boa resistência mecânica, tronco retilíneo, diâmetro médio do tronco superior a $30 \mathrm{~cm}$, livre de nós, livre de bolsas de resinas.

b) Madeira de qualidade para produção de carvão, deve possuir baixo teor de celulose, alto teor de lignina, densidade elevada.

c) Para celulose e papel a madeira deve possuir alto teor de celulose, baixo teor de lignina, baixa densidade.

d) Se a madeira a ser produzida for destinada a construção civil ou rural, essa deve ter alta densidade, alta resistência mecânica, possuir tronco retilíneo, alta durabilidade.

Devido ao forte crescimento do setor florestal no Brasil e no mundo, surgiu a necessidade de se produzir madeira com qualidade para uma determinada finalidade com o mínimo de perdas nos processos de produção e consequentemente melhorar o aproveitamento da área, minimizando a pressão sobre a mata nativa. É de suma importância compilar as informações disponíveis a respeito dos tratos silviculturais e seus efeitos na produtividade e qualidade da madeira do gênero Eucalyptus, para que se possa realizá-los de forma correta e produzir madeira com qualidade. Neste intuito, o objetivo desse trabalho é identificar, em literatura pertinente ao assunto, os efeitos dos tratos silviculturais na produtividade e na qualidade da madeira de Eucalyptus spp. em florestas equiâneas.

\section{Espaçamento}

O espaçamento, ou densidade de plantio é provavelmente uma das principais técnicas de manejo que visa a qualidade e a produtividade da matéria-prima. Deve ser definido em função dos objetivos do plantio, considerando-se que a influência do espaçamento é mais expressiva no crescimento em diâmetro do que em altura. $\mathrm{O}$ planejamento da densidade de plantio também deve visar a obtenção do máximo de retorno financeiro por área (Berger et al., 2002).

Se a densidade de plantio for muito baixa, as árvores não aproveitarão todos os recursos como água, nutrientes e luz disponíveis e, consequentemente, haverá menor produção de madeira por unidade de área. Caso a densidade de plantio seja elevada, tais recursos não serão suficientes para atender a demanda do povoamento, o que também repercutirá no decréscimo de volume de madeira e na qualidade das árvores. Normalmente os plantios são executados com espaçamentos variando entre $3 \times 2,3 \times 3,3 \times 4$ e $3 \times 5$ metros, os quais favorecem os tratos culturais mecânicos (Oliveira Neto et al., 2003).

Empresas moveleiras destinam a madeira dos primeiros desbastes para energia ou celulose, e as árvores remanescentes do povoamento, com porte mais expressivo, são utilizadas para a fabricação de serrados ou para a laminação (Berger, 2002).

Segundo Berger (2002), os plantios com espaçamentos maiores (densidade baixa de plantas por hectare) têm as características específicas abaixo:

a) maior produção de madeira em volume individual;

b) menor custo de implantação; 
c) maior número de tratos culturais;

d) maior conicidade de fuste;

e) desbastes tardios.

Os plantios com espaçamentos menores (alta densidade de plantas por hectare) possuem as seguintes características (Mello et al., 1971):

a) maior produção de madeira em volume por hectare;

b) rápido fechamento do dossel (menor número de tratos culturais);

c) menor conicidade do fuste.

O espaçamento além de ter influência na produção de madeira afeta significativamente os custos de implantação, manutenção e exploração da floresta, afetando a qualidade da madeira produzida (Mello et al., 1976).

Segundo Berger (2000), as vantagens da adoção de espaçamentos amplos são as seguintes:

a) as árvores apresentam maior desenvolvimento individual, permitindo sua utilização para fins mais nobres;

b) maior facilidade de mecanização de várias operações agrícolas após o plantio;

c) maior facilidade de mecanização florestal, como tratos culturais, melhorando a qualidade das árvores plantadas;

d) na colheita há maior facilidade na extração de lenha;

e) diminuição da taxa de mortalidade;

f) menor proporção de árvores dominadas.

Existem algumas vantagens no uso de um espaçamento inicial reduzido, visto que proporciona um número elevado de árvores jovens, o que permite uma boa seleção das melhores, quando das primeiras operações de limpeza e desbaste, isto no caso de plantio de mudas via propagação seminífera, no caso de plantios clonais há uma certa homogeneidade entre os indivíduos do povoamento. Um espaçamento menor promove um processo eficiente de desrama natural, do que resulta madeira de boa qualidade a ser obtida no estágio final de manejo do povoamento. Assim, o plantio em espaçamento reduzido teria a vantagem de proporcionar uma cobertura eficiente do solo pelas copas das árvores em um estágio inicial, de modo que por um tempo o solo é protegido e o desenvolvimento de ervas daninhas é suprimido (Berger et al., 2002).

Segundo Berger (2000), o espaçamento 3 x $2 \mathrm{~m}$ é o mais indicado quando a utilização da madeira for para celulose ou energia, compatibilizando a produção de árvores de dimensões mais adequadas a uma maior produção por unidade de área na idade de corte.

Já para utilização da madeira em serraria o espaçamento inicial é 3 x $2 \mathrm{~m}$ realizando um desbaste aos 4, 7, 11 e 15 anos com corte final da floresta aos 20 anos (Berger, 2000).

O espaçamento tem influência marcante na produção e qualidade da madeira. É preciso tomar toda a precaução para decidir sobre o espaçamento inicial, principalmente no manejo de povoamentos de eucalipto cujo objetivo é a produção de madeira industrial de rápido crescimento e densidade adequada. As decisões sobre espaçamentos não podem ser tomadas sem o conhecimento mais preciso da influência dos mesmos na qualidade dos produtos obtidos (Mello et al., 1976).

\section{Controle de plantas invasoras}

Plantas invasoras são plantas que nascem em local não desejado, e causam prejuízos às plantas cultivadas devido à competição por água, luz e nutrientes. Os métodos possíveis de serem utilizados para eliminar tais plantas são a capina manual na linha de plantio, conjugada com roçada mecânica nas entrelinhas, ou, apenas capina manual na linha e entrelinha (Toledo et al.,2003). 
Pode-se ainda utilizar herbicidas em cobertura total ou apenas na linha de plantio, para o necessário controle em plantios novos. Para plantios adultos, podemos incluir as roçadas manuais ou mecânicas e a utilização de herbicidas. Nos dias atuais é muito comum a utilização de herbicidas em florestas, pois, as outras formas de controle das plantas invasoras são por demais conhecidas no meio florestal. O emprego de produtos químicos para a destruição dessas plantas aumenta progressivamente. Isto se deve, principalmente, à falta e elevado custo de mão de obra no meio rural (Pitelli, 1982).

Para que esse manejo seja eficaz, é necessário determinar a densidade das plantas invasoras que competem com o eucalipto, bem como o período em que a cultura deve ser mantida sem a presença dessas plantas (Dinardo et al., 2003).

Segundo Toledo et al. (2003), as plantas invasoras competem com a cultura do eucalipto durante todo seu ciclo, mas é na fase inicial que ocorrem danos mais significativos.

Dinardo et al. (2003) mencionam que a remoção das plantas invasoras apresenta o mesmo efeito sobre o desenvolvimento em diâmetro das plantas, quando comparado com a aplicação de fertilizante. A combinação desses dois tratamentos é sensivelmente superior aos tratamentos efetuados isoladamente. Deve-se salientar ainda, que o efeito das plantas invasoras se manifesta, principalmente, no início do desenvolvimento da floresta, competindo com as mudas por luz, água e nutrientes minerais.

\section{Fertilização}

Fertilização é o processo pelo qual se busca disponibilizar nutrientes para cada cultura devido ao baixo teor dos mesmos no solo. Essa prática é recomendada, conforme os resultados das análises de solo realizadas em laboratório e de acordo com as exigências da espécie selecionada (Berger, 2000).

Berger et al. (2002), afirmam que a fertilização é a ferramenta mais comum e talvez de ação mais efetiva que se dispõe para melhorar a qualidade do solo e, com isto, aumentar a taxa de crescimento vegetativo. A quantidade, tipo e a época de aplicação dos fertilizantes podem vir a ocasionar alterações na qualidade da madeira, sendo que estas mudanças dependem da espécie e da fertilidade do solo.

Posey (1964); Klem (1968) e Higs \& Rudman (1973) apud Pinheiro (1999) afirmam que a prática de fertilização em povoamentos florestais pode alterar a estrutura anatômica e a constituição química da parede celular, alterando a densidade da madeira.

A fertilização é a ferramenta mais comum e talvez de ação mais efetiva que se dispõe para melhorar a qualidade do solo e, com isto, aumentar a taxa de crescimento das plantas. A quantidade, tipo e a época de aplicação dos fertilizantes podem ocasionar alterações na qualidade da madeira, sendo que estas mudanças dependem da espécie e da fertilidade do solo. Quanto à época de aplicação de fertilizantes, normalmente se faz durante o plantio das mudas e isso não interfere na qualidade da madeira das árvores adultas (Berger, 2000).

Estas árvores tendem a produzir maior proporção de lenho juvenil, caracterizado pela baixa resistência e densidade, paredes celulares mais finas, mais celulose e menos lignina. Além disso, a adubação de plantio proporcionou um aumento significativo na produção volumétrica de $E$. grandis e E. saligna, com resultados superiores àqueles encontrados para adubação parcelada. A primeira apresentou melhores respostas à adubação, enquanto a segunda respondeu melhor aos diferentes espaçamentos (Lima, 2005). 
Segundo Berger (2000) os nutrientes abaixo são importantes para as plantas da seguinte forma:

a) Nitrogênio $(\mathrm{N})$

É o elemento mais importante para a elaboração de substâncias no interior da célula e na clorofila, sendo, portanto, fundamental para os processos vitais da planta;

b) Fósforo (P)

Mantém o crescimento das raízes, da inflorescência e das sementes, favorece o processo de lignificação e é importante para a atividade da microflora e microfauna do solo;

c) Potássio $(\mathrm{K})$

Influencia a atividade das enzimas, regula o balanço de água das plantas e é componente indispensável para a constituição da celulose e do processo de lignificação;

d) Cálcio $(\mathrm{Ca})$

Atua como regulador dos nutrientes das plantas, protege a formação da clorofila, tem importância como elemento da estrutura das plantas e é um bom desacidificador do solo;

e) Magnésio $(\mathrm{Mg})$

Atua na formação das clorofilas e conseqüentemente tem influência na fotossíntese.

Os resultados obtidos por Mello et al. (1976) com Eucalyptus saligna Sm. revelam que a fertilização mineral teve ação positiva e pronunciada sobre o desenvolvimento das árvores plantadas em solo pobre e ácido de cerrado. Aos 2 anos de idade a diferença de produção entre as parcelas adubadas e não adubadas era de $33 \mathrm{~m}^{3} \mathrm{ha}^{-1}$, não tendo sido constatado efeito prejudicial da adubação na qualidade da madeira produzida sob efeito dos tratamentos fertilizantes.

Lima (2005) estudou o efeito da aplicação de NPK e calcário sobre a qualidade da madeira de Eucalyptus saligna e verificou que a densidade básica, a espessura e o comprimento das fibras não foram afetados pela aplicação dos macronutrientes primários, com exceção feita à aplicação de calcário ( 2 t. ha ${ }^{-1}$ ) que reduziu significativamente o comprimento das fibras.

O cálcio tem função estrutural sendo encontrado em abundância na lamela média das fibras, e é responsável pelo aumento da rigidez da parede celular, dificultando o aumento do volume celular (Lima, 2005).

Estudando a influência da fertilização na produtividade florestal Paes et al. (2007), constatou que houve uma redução de $5 \%$ na densidade da madeira, mas um aumento de $35 \%$ na produtividade. Isto torna-se muito atrativo do ponto de vista da indústria de papel, mas deve-se ter em conta que uma diminuição de $5 \%$ da densidade da madeira produziria uma redução de 10 a $20 \%$ da resistência da madeira à flexão e dureza.

Em relação à acidez do solo, a maioria das espécies de eucalipto cultivadas no Brasil é tolerante ao alumínio, contudo a disponibilidade de cálcio em solo deve ser alta, por se tratar do nutriente que mais acumula em folhas, ramos e caule. Daí, a necessidade de se realizar a calagem visando suprir de modo adequado esse nutriente à cultura (Silva et al., 2007).

Segundo Valeri et al. (1985), a calagem em solos ácidos vem com o objetivo de corrigir a acidez e aumentar a disponibilidade de Ca e/ou Mg. Os mesmos autores estudarem os efeitos da aplicação de micronutrientes na presença ou ausência de calcário em $E u$ calyptus saligna, verificaram que as parcelas com calcário apresentaram uma altura média de 3,20 m, à idade de 15 meses, enquanto que as parcelas não submetidas à calagem apresentaram plantas com altura média de $2,75 \mathrm{~m}$.

Mello et al. (1976), estudando os efeitos da aplicação de N, P, K e calcário dolomítico em Eucalyptus saligna, verificaram que o $\mathrm{P}$ foi o elemento que proporcionou maior produção volumétrica de madeira aos 5 anos de idade. 
Tomazelo Filho (2006), estudando os efeitos da irrigação e fertilização no aumento da produtividade da floresta verificou um aumento na ordem de 30 e $36 \%$ no volume do lenho em parcelas submetidas a essas práticas associadas, observando ainda, mudanças significativas nos aspectos anatômicos da madeira (espessura cerne/alburno, variação no comprimento de fibras e vasos, densidade do lenho, variação radial, dentre outras). Enfim, este autor observou mudanças significativamente positivas na qualidade da madeira, em parcelas submetidas à prática associada de irrigação e fertilização.

\section{Desrama}

Desrama é o processo de desprendimento do galho do tronco e esse processo pode ser natural ou artificial (Polli, 2005). Pode acontecer de maneira natural, em consequência da senescência, morte e posterior desprendimento dos ramos da base da árvore, ou, pode ser artificial, por meio da remoção dos galhos vivos e mortos das árvores até 1,5m (acima do solo) na base da árvore (Vale et al., 2002).

A desrama natural se realiza por influência de agentes físicos e bióticos e se processa em quatro etapas distintas: supressão, morte e queda dos galhos; seguida da oclusão da base do ramo. O início e a intensidade da desrama natural dependem da espécie, da competição entre copas e das condições climáticas locais (Polli, 2005). O processo de desprendimento dos galhos mortos do fuste, de modo geral, é lento, há espécies que mantêm os ramos mortos aderidos ao tronco por muitos anos, desqualificando a madeira, devido à formação de nós mortos, negros ou soltos (Finger et al., 2001).

Em geral, utilizando-se a desrama artificial produz-se madeira de melhor qualidade, livre de nós (Vale et al., 2002). Finger et al. (2001) consideram que em geral, por meio da desrama artificial produz-se madeira de melhor qualidade, livre de nós. Em povoamentos florestais, nos quais algumas árvores venham a ser utilizadas para a produção de madeira serrada e laminação, é recomendável o uso da desrama artificial para a obtenção de madeira de qualidade, com maior resistência mecânica (Polli, 2005).

Segundo Finger et al. (2001) em povoamentos florestais, que algumas árvores venham a ser utilizadas para a produção de madeira serrada e laminação, é recomendável o uso da desrama artificial para a obtenção de madeira de qualidade, com maior resistência mecânica.

A remoção de ramos vivos reduz a superfície fotossinteticamente ativa da planta, embora possa reduzir, também, a respiração. Ou seja, a retirada dos ramos inferiores tem a vantagem de reduzir o consumo de reservas pela respiração. Os ramos da base das árvores, removidos pela desrama artificial, por contribuírem pouco com a fixação de carbono, permitem balanço favorável na relação produção/consumo de assimilados. Também, promove redução na perda de água por transpiração, o que é importante principalmente em regiões onde ocorre o déficit hídrico (Polli, 2005).

Quando não se realiza a desrama dos galhos secos além da presença de nós que deixam no fuste, estes nós facilitam a entrada de fungos, que podem comprometer a qualidade da madeira (Vale et al., 2002).

\section{Desbaste}

Os desbastes são cortes parciais de árvores no povoamento, realizados a partir do fechamento do dossel. Para se ter controle sobre a época adequada para realizar os desbastes usa-se como indicador a área basal. Embora esta grandeza seja largamente empregada para esse fim, se tomada isoladamente, pode não descrever o real grau de 
competição entre as árvores, o que se torna evidente, em sítios com diferentes capacidades de produção (Schneider et al., 1998).

Para a regulação da densidade e do grau de competição, o desbaste é empregado, pois permite ampliar o espaço vital e, com isso, obter um maior crescimento em diâmetro das árvores remanescentes, permitindo que o terreno seja ocupado por árvores de melhor qualidade e sanidade (Finger \& Schneider, 1999).

Com a execução de desbaste o espaço vital para cada árvore é aumentado proporcionando o desenvolvimento equilibrado da copa e do sistema radicular de acordo com a dimensão da árvore. Entretanto, os desbastes muito pesados podem levar ao aumento desproporcional do tamanho da copa e dos galhos vindo a reduzir a qualidade da madeira bem como, de forma geral, reduzem a produção volumétrica da floresta. Por outro lado, desbastes de intensidade adequada, aplicados no momento certo permitem melhorar a qualidade da madeira, homogenizar os sortimentos e aumentar a dimensão das árvores sem levar a perdas significativas de volume (Schneider et al., 1998).

A intensidade de desbaste, representada pelo peso de desbaste (percentagem a ser retirada) e ciclo (período entre duas intervenções de desbaste) deve ser definida segundo caracteres técnicos e econômicos, observados os objetivos da produção em cada secção da floresta, pois nas secções tem-se a mesma espécie e mesma capacidade de produção (sítio florestal) (Finger \& Schneider, 1999).

De forma geral, pode-se afirmar que o primeiro e o segundo desbaste determinam o tipo, a qualidade e a quantidade de madeira a ser obtida por ocasião da colheita final. Desbastes trazem a redução da produção total da floresta, no entanto permitem o maior crescimento das árvores individuais e, com isso, o aumento do valor das mesmas, devido ao melhor aproveitamento industrial, entre outros (Lima, 2005).
Schneider et al. (1998), analisando a reação de povoamentos submetidos a desbastes, observaram que as árvores remanescentes aumentavam rapidamente o incremento, devido ao melhor aproveitamento dos fatores ambientais, denominando esta observação como efeito de aceleração de crescimento. Este efeito é dependente da idade de aplicação dos desbastes e do peso dos mesmos, sendo que desbastes realizados na fase juvenil tendem a produzir, temporariamente, maior crescimento (Lima, 2005).

\section{Considerações Finais}

O espaçamento afeta o crescimento das árvores em diâmetro, e altura. Além de alterar a densidade da madeira e o comprimento das fibras. $\mathrm{O}$ controle de plantas invasoras influencia intensamente o desenvolvimento das plantas principalmente na fase inicial, pois diminui a competitividade por água, luz e nutrientes minerais. Segundo informações obtidas, pode-se concluir que a escolha do espaçamento inicial deve ser feita com base no destino final da madeira a ser produzida, pois este pode influenciar nos custos de manutenção, crescimento das árvores em diâmetro e altura. Árvores com espaçamento mais amplos dentro de certos limites, crescem mais rapidamente, por outro lado tendem ao enforquilhamento devido a ação dos ventos, maior tortuosidade. Espaçamentos reduzidos tendem a produzir uma maior quantidade de árvores podendo selecionar as de melhor qualidade e sanidade.

A fertilização afeta o desenvolvimento das plantas, a densidade da madeira, a quantidade de celulose e lignina. Antes de implantar uma cultura é necessário realizar uma análise do solo e conhecer a exigência nutricional da espécie a ser implantada, para assim disponibilizar à cultura os nutrientes através da fertilização.

Plantas submetidas a desrama artifi- 
cial têm menos perda de água nas épocas secas, sendo uma vantagem principalmente em regiões onde ocorre déficit hídrico. Quando o objetivo é produzir madeira para serraria, faz-se necessário a realização da desrama artificial, dando origem a uma madeira com boa resistência mecânica e livre de nós.

O controle de plantas invasoras deve ser realizado durante todo ciclo da cultura, pois essas plantas exercem uma grande competição por água, luz e nutrientes com a cultura, mas é na fase inicial que essa competição é mais acentuada, pois a cultura ainda não está estabelecida.

$\mathrm{O}$ desbaste tem a vantagem de selecionar plantas com melhor qualidade e sanidade, aumentando a espaço vital das plantas remanescentes, para que essas tenham um melhor desenvolvimento em diâmetro.

Enfim, com a combinação dos tratos silviculturais de forma correta e na época adequada, é possível produzir madeira de qualidade.

\section{REFERÊNCIAS BIBLIOGRÁFICAS}

BERGER, R. Crescimento e qualidade da madeira de um clone de Eucalyptus saligna Smith sob o efeito do espaçamento e da fertilização. 2000. Xp. Dissertação (Mestrado em Engenharia Florestal) - Universidade de Santa Maria.

BERGER, R. B.; SCHNEIDER, P. R.; FINGER, C. A. G.; HASELEIN, C. R. Efeito do espaçamento e da adubação no crescimento de um clone de Eucalyptus saligna Smith. Revista Ciência Florestal, v. 12, n. 2, p. 75-87, 2002.

DINARDO, W.; TOLEDO, R. E. B.; AGUIAR ALVES, P. L. C.; PITELli,R.A. Efeito da densidade de plantas de Panicum maximum Jacq. Sobre o crescimento inicial de Eucalpytus grandis W. Hill ex Maiden. Scientia Foretalis, n. 64, p. 59-68, dez. 2003.
FINGER, C. A. G., SCHNEIDER, P. R. Determinação do peso do desbaste para florestas de Eucalyptus grandis Hill ex Maiden, com base no índice de espaçamento relativo. Ciência Florestal, Santa Maria, v. 9, n. 1, p. 79-87, 1999.

FINGER, C. A. G.; SCHNEIDER, P. R.; BAZZO, J. L.; KLEIN, J. E. M. Efeito da intensidade de desrama sobre o crescimento e a produção de Eucalyptus saligna Smith. Revista Cerne, Lavras (MG), v. 7, n. 2, p. 5364, 2001.

LIMA, I. L.; GARCIA, J. N.; NOGUEIRA, M. C. S. Influência do desbaste nas tensões de crescimento de Eucalyptus Grandis Hill ex Maiden. Scientia Forestalis, v. 58, p. 111$125,2000$.

LIMA, I. L.; GARCIA, J. N. Influência do desbaste em propriedades físicas e mecânicas da madeira de Eucalyptus grandis Hill ex Maiden. Revista do Instituto Florestal, São Paulo, v. 17, n. 2, p. 151-160, 2005.

LIMA, I. L. Influência do desbaste e da adubação na qualidade da madeira serrada de Eucalyptus grandis Hill ex Maiden. 2005. Xp. Tese (Doutorado em Recursos Florestais) - Universidade de São Paulo, Piracicaba.

MELLO, H. A. et al. Influência do espaçamento na produção de madeira de eucalipto em solo de cerrado. IPEF, n. 2/3, p. 3-30, 1971

MELLO, H. A.; SIMÕES, J.W.; FERREIRA, C. A.; BRASIL,U.M. Influência do espaçamento e da idade de corte na produção de madeira de eucalipto em solo de cerrado. IPEF, v. 13, p. 143-62, 1976.

OLIVEIRA NETO, S. N. et.al. Produção e distribuição de biomassa em Eucalyptus $\mathrm{Ca}$ - 
maldulensis Dehn. em resposta à adubação e ao espaçamento. Revista Árvore, ViçosaMG, v.27, n. 1, p. 15-23, 2003.

PAES, M. F.; LIMA, I. L.; GARCIA, J.N.; FLORSHEIM, S.M.B. Efeito da fertilização na variação da densidade básica e densidade aparente em função da posição radial na árvore de Eucalyptus grandis. Instituto Florestal, São Paulo, n. 31, p. 21-25, jul. 2007.

PINHEIRO, A. L. Considerações sobre taxonomia, filogenia, ecologia, genética, melhoramento florestal e a fertilização mineral e seus reflexos na anatomia da madeira. SIF, Viçosa, MG, 144 p., 1999.

PITELLI, R.A. - Manejo integrado de plantas daninhas. In: Controle integrado de plantas daninhas. São Paulo, Editora do CREASP, 1982. p. 28-41

POLLI, Q. H. Crescimento e qualidade da madeira para serraria em clone de $E$ ucalyptus grandis [Hill ex Maiden] submetido à desrama artificial. 2005. Xp. Dissertação (Mestrado em Ciência Florestal) - Universidade Federal de Viçosa.

SCHNEIDER, P. R.; FINGER, C, A, G.; HOPPE, J.M.; DRESCHER, R. ; SCHEEREN, L.W.; MAINARDI,G.; FLEIG, F.D. Produção de Eucalyptus grandis Hill ex Maiden em diferentes intensidades de desbaste. Ciência Florestal, v. 8, n. 1, p. 129-140, 1998.

SILVA, C. A.; RANGEL, O. J. P.; BELIZÁRIO, M. H. Interação calagem-adubação fosfatada e sua influência nos níveis críticos de $\mathrm{P}$ e crescimento do eucalipto. Scientia Forestalis, n. 73, p. 63-72, março 2007.
TOLEDO, R. E. B. Faixas e períodos de controle de plantas daninhas e seus reflexos no crescimento do eucalipto. 2002. Xp. Dissertação (Doutorado em Agronomia) Universidade de São Paulo, Piracicaba.

TOLEDO, R. E. B.; FILHO, R.V.; BEZUTTE, A.J.; PITELLI, R. A.; AGUIAR ALVES, P. L. C.; VALlE, C. F.; ALVARENGA, S. F. Períodos de controle de Brachiaria $s p$ e seus reflexos na produtividade de Eucalyptus grandis. Scientia Forestalis, n. 63, p. 221232, jun. 2003.

TOMAZELO FILHO, M. Efeito da irrigação e fertilização nas propriedades do

lenho de árvores de Eucalyptus grandis $\mathbf{x}$ urophylla. 2006. 135f. Tese (Livre Docência) - Escola Superior de Agricultura "Luiz de Queiroz", Universidade de São Paulo, Piracicaba, 2006.

VALE, R.S. Efeito da desrama artificial no crescimento e na qualidade da madeira de clones de eucalipto, em sistema agro-silvopastoril. 2000. 96f. Dissertação (Mestrado em Engenharia Florestal) - Universidade Federal de Lavras, Lavras, 2000.

VALE, R. S.; MACEDO, R. L. G., VENTURIN, N.; MORI, F.A.; MORAIS, A. R. Efeito da desrama artificial na qualidade da madeira de clones de eucalipto em sistema agrossilvipastoril. Revista Árvore, v. 26, n. 3, p. 285 297, Viçosa-MG, 2002.

VALERI, S. V.; CORRADINI,L.; AGUIAR, I. B; SOUZA, E. C. A; BANZATTO, D. A. Efeitos do fósforo e calcário dolomítico no desenvolvimento inicial de Eucalyptus grandis Hill ex Maiden plantado em um regossolo. IPEF n. 29, p. 55-60,1985. 